\title{
Endocan removal during continuous renal replacement therapy: does it affect the reliability of this biomarker?
}

\author{
Patrick M. Honore ${ }^{1 *}$, David De Bels ${ }^{1}$, Rachid Attou', Sebastien Redant ${ }^{1}$, Andrea Gallerani ${ }^{1}$ and Kianoush Kashani ${ }^{2}$ \\ This comment refers to the article available at https://doi.org/10.1186/s13054-018-2222-7.
}

We read the narrative review by De Freitas Caires et al. with great interest [1]. Acute kidney injury (AKI) is prevalent among patients with sepsis, and a substantial proportion of patients with sepsis-associated AKI (SA-AKI) require renal replacement therapy (RRT) [2]. Continuous RRT (CRRT) is increasingly used $(\sim 20 \%$ SA-AKI) among hemodynamically unstable septic shock patients [2]. Endocan as a novel endothelium-derived soluble dermatan sulfate proteoglycan has a molecular mass of around $20 \mathrm{kDa}$ [3]. The contemporary CRRT membranes are able to remove molecules as large as 35 $\mathrm{kDa}$. Hence, endocan could be removed by CRRT [4]. When new highly adsorptive membranes (HAM) with high absorptive abilities are used, the ability of CRRT to eliminate endocan could be even enhanced [4]. Therefore, the reliability of endocan during CRRT could be altered. De Freitas Caires et al. show that endocan appeared as a consistent good diagnostic criterion as well as procalcitonin (PCT) and could potentially be used for de-escalation therapy in the future (requiring new studies obviously) as PCT. Accordingly (if endocan is used for de-escalation in the future), falsely low endocan in CRRT patients, in turn, could lead to an earlier de-escalation of antibiotics and level of care for septic patients. There has been no investigation on the performance of endocan on patients who receive CRRT. Therefore, we believe there is a critical need for a future study with a focus on the performance of the currently known sepsis biomarkers among those who receive CRRT [5].

\footnotetext{
* Correspondence: Patrick.Honore@CHU-Brugmann.be

${ }^{1}$ ICU Department, Centre Hospitalier Universitaire Brugmann, Place Van Gehuchtenplein,4, 1020 Brussels, Belgium

Full list of author information is available at the end of the article
}

\begin{abstract}
Abbreviations
AKI: Acute kidney injury; CRRT: Continuous renal replacement therapy; HAM: Highly adsorptive membranes; PCT: Procalcitonin; RRT: Renal replacement therapy; SA-AKI: Sepsis-associated AKI
\end{abstract}

Acknowledgements

None.

Funding

None.

Availability of data and materials Not applicable.

\section{Authors' contributions}

$\mathrm{PMH}$ and KK designed the paper. All authors participated in drafting the manuscript. All authors have read and approved the final version.

Ethics approval and consent to participate Not applicable.

\section{Consent for publication}

Not applicable.

\section{Competing interests}

The authors declare that they have no competing interests.

\section{Publisher's Note}

Springer Nature remains neutral with regard to jurisdictional claims in published maps and institutional affiliations.

\section{Author details}

${ }^{1}$ ICU Department, Centre Hospitalier Universitaire Brugmann, Place Van Gehuchtenplein,4, 1020 Brussels, Belgium. ${ }^{2}$ Division of Nephrology and Hypertension, Division of Pulmonary and Critical Care Medicine, Mayo Clinic, Rochester, USA.

Received: 20 April 2019 Accepted: 7 May 2019

Published online: 22 May 2019

\section{References}

1. De Freitas Caires N, Gaudet A, Portier L, Tsicopoulos A, Mathieu D, Lassalle P. Endocan, sepsis, pneumonia, and acute respiratory distress syndrome. Crit Care. 2018;22(1):280. https://doi.org/10.1186/s13054-018-2222-7.Review.

2. Peters E, Antonelli M, Wittebole $X$, Nanchal R, François B, Sakr Y, et al. A worldwide multicentre evaluation of the influence of deterioration or improvement of acute kidney injury on clinical outcome in critically ill patients with and without sepsis at ICU admission: results from The 
Intensive Care Over Nations audit. Crit Care. 2018;22(1):188. https://doi.org/ 10.1186/s13054-018-2112-z.

3. Lassalle P, Molet S, Janin A, Heyden JV, Tavernier J, Fiers W, et al. ESM-1 is a novel human endothelial cell-specific molecule expressed in lung and regulated by cytokines. J Biol Chem. 1996;271:20458-64.

4. Honoré PM, De Bels D, Spapen HD. An update on membranes and cartridges for extracorporeal blood purification in sepsis and septic shock. Curr Opin Crit Care. 2018;24(6):463-8. https://doi.org/10.1097/MCC. 0000000000000542.

5. Honoré PM, Jacobs R, De Waele E, Van Gorp V, Spapen HD. Evaluating sepsis during continuous dialysis: are biomarkers still valid? Blood Purif. 2014;38(2):104-5. https://doi.org/10.1159/000363497 Epub 2014 Oct 17. 